\title{
Análise das campanhas de prevenção às arboviroses dengue, zika e chikungunya do Ministério da Saúde na perspectiva da educação e comunicação em saúde
}

\author{
Analysis of the prevention campaigns against dengue, zika and \\ chikungunya arboviruses from the Ministry of Health from the health \\ education and communication perspective
}

\author{
Natália Fernandes de Andrade', Elizabeth Alves de Jesus Prado', Ádria Jane Albarado', Maria \\ Fátima de Sousa', Ana Valéria Machado Mendonça'
}

DOI: $10.1590 / 0103-1104202012621$

RESUMO Buscou-se analisar os cartazes das campanhas nacionais sobre dengue, zika e chikungunya realizadas pelo Ministério da Saúde entre 2013 e 2017 para prevenção das arboviroses. Trata-se de uma análise de conteúdo com abordagem qualitativa de 18 peças publicitárias coletadas no site da instituição. Para tanto, além dos dados textuais contidos nos cartazes, foram considerados os achados encontrados a partir da descrição das peças. As categorias temáticas analíticas que emergiram da observação do material foram: mobilização; orientação; e informação. Após o surgimento da chikungunya e da zika em 2014 e 2015, respectivamente, a instituição saiu da produção anual de 1 para 3,6 peças. O layout dos cartazes segue a lógica de técnicas de comunicação comercial, sem se preocupar com a diferença entre um produto mercantil e um direito universal. Não há articulação com as tecnologias de informação e comunicação, e os cartazes responsabilizam a população pela prevenção das doenças. Houve uma mudança nas mensagens sobre os cuidados, adotando-se a ênfase nas consequências e sequelas das arboviroses, não havendo espaço para educação e promoção da saúde. Constataram-se a transmissão de informações e a imposição de orientações, distante daquilo proposto pela comunicação educativa, que pressupõe ações pensadas conforme as necessidades dos usuários.

PALAVRAS-CHAVE Comunicação em saúde. Educação em saúde. Dengue. Zika vírus. Vírus chikungunya.

1 Universidade de Brasília (UnB) - Brasília (DF),

Brasil.

natalia.fandrades@gmail. com
ABSTRACT The posters of national campaigns on dengue, zika and chikungunya carried out by the Ministry of Health between 2013 and 2017 for the prevention of arboviruses were analyzed. It is a content analysis with a qualitative approach of 18 advertising pieces collected on the institution's website. Therefore, besides the textual data contained in the posters, the findings found from the description of the pieces were considered. The analytical thematic categories that emerged from the observation of the material were: mobilization; guidance; and information. After the emergence of chikungunya and zika in 2014 and 2015, respectively, the institution left its annual production from 1 to 3.6 pieces. The layout of the posters following commercial communication techniques logic, without worrying about the difference between a commercial product and a universal right. There is no link with information and communication technologies, and posters hold the population responsible for preventing diseases. The messages about care have changed, with an emphasis on the consequences and sequelae of arboviruses, with no room for education and health promotion. The transmission of information and the imposition of guidelines were found, far from what is proposed by educational communication, which presupposes actions designed according to the needs of users.

KEYWORDS Health communication. Health education. Dengue. Zika virus. Chikungunya virus. 


\section{Introdução}

O presente estudo traz uma análise das campanhas midiáticas realizadas pelo Ministério da Saúde (MS) brasileiro para prevenção e combate ao vetor das arboviroses dengue, zika e chikungunya enquanto agravos sociais e reflexões sobre como as informações transmitidas pelos cartazes dessas campanhas refletem, ou não, a comunicação educativa e a promoção da saúde. Sabe-se que o debate teórico acerca da informação, educação e comunicação é vasto, por isso, não se pretende esgotá-lo, mas apresentar a comunicação educativa como forma de prevenção e promoção em saúde.

Para tanto, alguns conceitos são essenciais nessa apresentação. No campo da comunicação, campanhas são definidas como dispositivos estratégicos de gestão que visam

[...] alcançar uma meta definida a partir da integração de uma série de instrumentos e ações, em um prazo previamente determinado, com um objetivo claramente definido ${ }^{1(7)}$.

Na saúde, são utilizadas, pelo menos, desde 1920 nas primeiras campanhas de vacinação². Uma ferramenta bastante utilizada em campanhas é o cartaz, qualquer mensagem publicitária gráfica impressa em papel ou outro material, cujo tamanho, forma, arte, cores, disposição das informações e todas as outras características são personalizáveis conforme a intencionalidade e a mensagem que se deseja transmitir ${ }^{3}$. Em geral, esses materiais gráficos são fixados em locais públicos onde há grande circulação de pessoas que se deseja alcançar. É um dos produtos mais comuns da publicidade e da propaganda, usado histórica e tradicionalmente em campanhas de saúde 2 .

Segundo a Organização Mundial da Saúde (OMS), cerca de 4 bilhões de pessoas no mundo são suscetíveis à infecção pelo vírus da dengue; e, entre os estados-membros da Organização, o número de notificações passou de 2,2 milhões em 2010 para 3,2 milhões em 2015, havendo evidências de que o número total de infectados pelo vírus da dengue chegue a 390 milhões de pessoas por ano ao redor do mundo 4 , o que torna dengue, zika e chikungunya um dos maiores problemas de saúde pública global. Em 2017, a taxa de incidência de dengue foi de 116 casos para cada 100 mil habitantes no Brasil. No mesmo ano, $41 \%$ dos municípios do Nordeste estavam em alerta. No referido período, o MS investiu R \$ 17,6 milhões em estratégias de prevenção. As condições climáticas, de saneamento, desmatamento, urbanização e migração populacional também corroboraram para o agravamento desse quadro ${ }^{5}$.

No que se refere à prevenção, trata-se de um conjunto de intervenções cuja finalidade é evitar o surgimento de doenças específicas, diminuindo sua incidência e prevalência, em geral, com base em dados epidemiológicos ${ }^{6}$. A promoção da saúde foi definida pela Carta de Ottawa como o processo de proporcionar às pessoas os meios necessários para melhorar sua saúde e exercer maior controle sobre ela ${ }^{7}$. Essa definição implica ações permanentes que comprometem todos os atores da sociedade com intenção explícita de fortalecer habilidades de indivíduos e grupos por meio de um processo político e social ${ }^{8}$.

É nesse contexto que a comunicação educativa se apresenta. Todavia, antes de abordar seu conceito em específico, é necessário assumir o imbricamento das ações de informação, educação e comunicação e que estas contribuem significativamente na interlocução com as comunidades, pois possuem elementos convergentes e interagem no processo de transformação social ou mudança de um fenômeno. Entende-se como informação em saúde o conteúdo ou conhecimento que orienta a tomada de decisão, o qual pode se dar na forma de dados orais ou textuais e subsidiar tanto a tomada de decisão de usuários quanto a de profissionais, pesquisadores e gestores.

No que tange à comunicação em saúde, a partir da revisão de conceitos de mais de 20 teóricos do campo nos últimos 20 anos, compreende-se que se refere a processos dialógicos e à utilização de estratégias comunicacionais que 
respeitam os direitos à informação, à educação e à saúde, tendo como finalidades a prevenção de enfermidades, $o$ incentivo à cidadania e à transparência na gestão, bem como a promoção da melhoria da qualidade de vida das pessoas em seus diferentes contextos sociais, por meio das mídias, da produção do conhecimento científico e das relações interpessoais ${ }^{9}$.

A educação em saúde, por sua vez, orienta a população para que ela viva de maneira saudável. As ações de educação em saúde devem ser realizadas de acordo com a realidade dos indivíduos, das famílias e da comunidade, por meio das experiências e vivências dos sujeitos envolvidos em cada processo. Nesse sentido, a abordagem adotada se afasta de definições restritas à formação profissional do campo da saúde e se aproxima daquela voltada ao conjunto de práticas que estimulam a autonomia das pessoas para o cuidado individual e coletivo, identificando as suas principais necessidades. Além disso, está intimamente relacionada com a promoção da saúde e, no âmbito escolar, parte de uma visão integral e multidisciplinar do ser humano, que considera as pessoas em seu contexto familiar, comunitário, social e ambiental10.

Desse modo, entende-se que não é possível comunicar sem uma informação inicial; e estas se relacionam ${ }^{11}$ à educação com o agir do indivíduo. Contudo, não devem ser utilizadas como meros instrumentos no processo de educar. Mesmo que estejam associadas, a ação do educar deve ser feita pela comunicação, e não para a comunicação ${ }^{12}$. Esses conceitos se consolidam no cotidiano dos serviços de saúde e são imprescindíveis quando se analisam as práticas profissionais para o alcance da saúde em seu conceito mais amplo. Isso porque, para alcançar um estado saudável, o indivíduo precisa ser o protagonista do seu cuidado - o que somente pode ser alcançado por meio da educação, pois, apenas ela é capaz de promover mudanças nas práticas sociais e individuais.

Ao teorizar sobre a educação libertadora, Paulo Freire expõe que esta transcende a simples esfera do conhecimento de regras, métodos e linguagens e vai ao encontro da tradução do conhecimento disponível e ressignificação conforme o universo em que o indivíduo habita, motivando assim a tomada de consciência e possível mudança de hábito ou comportamento ${ }^{13}$. Como os esforços e maior parte do investimento do governo se dão por meio de ações descontinuadas e a partir de modelos campanhistas e curativos, o Brasil ainda não consegue conter problemas de saúde pública que demandam apropriação de conhecimentos, protagonismo individual e coletivo no cuidado à saúde, no caso, as arboviroses.

Apresenta-se a comunicação educativa, portanto, como um caminho para o combate ao vetor e à prevenção das arboviroses. Baseada no conhecimento gerado a partir da tradução da informação e sua relação com a comunicação, a comunicação educativa orienta-se pelo ordenamento das relações pessoais dos envolvidos, educandos e docentes, ou não ${ }^{4}$. Trata-se de um processo de escuta que busca identificar as necessidades individuais e da comunidade para direcionar ações de transformação, tendo como centro os referidos indivíduos e comunidades como protagonistas desse processo.

Tendo em vista a necessidade de ações de comunicação educativa para a transformação das práticas em saúde voltadas ao controle do vetor Aedes aegypti e o investimento de aproximadamente $\mathrm{R} \$ 190$ milhões por parte do MS em campanhas para combate e prevenção das arboviroses dengue, zika e chikungunya - e ainda febre amarela -, entre 2013 e $2017^{9}$, apresenta-se a análise do formato cartaz das campanhas realizadas pelo MS para o combate e prevenção da dengue, zika e chikungunya no período de 2013 a 2017. Busca-se compreender se a utilização das peças tem a educação e promoção da saúde como objetivo.

\section{Roteiro metodológico}

Trata-se de uma pesquisa qualitativa com foco na interpretação dos cartazes produzidos para as campanhas do MS sobre o tema das 
arboviroses dengue, zika e chikungunya no período de 2013 a 2017. O recorte temporal justifica-se pelo surgimento das novas enfermidades também transmitidas pelo vetor Aedes, em 2014 e 2015, chikungunya e zika, respectivamente.

Conforme orientam Miranda e Simeão ${ }^{\mathbf{1 4}}$, partiu-se da identificação da tipologia, conteúdo, formato e suporte do que foi produzido pelo MS para fins de campanha de comunicação de massa, utilizando-se da pesquisa documental nas bases de dados da pasta ministerial. A análise das campanhas impressas não foi realizada, pois a instituição não possui acervo físico dos materiais em questão.

A coleta de dados foi realizada no endereço eletrônico institucional ${ }^{15}$ obedecendo a um processo de identificação, categorização e tratamento para análise posterior. No total, foram identificadas e coletadas 18 peças, sendo: 1 em 2013; 6 em 2014; 3 em 2015; e 4 em 2017 e em 2018. Como técnica de análise, optou-se pela análise de conteúdo, tendo como premissa as campanhas anteriormente estudadas por Vasconcelos ${ }^{16}$.

Foi elaborada uma matriz com a descrição do material e informações encontradas nos documentos. Nela, foram registrados os seguintes dados: ano de publicação da campanha; descrição do cartaz analisado (cores, imagens e disposição das informações); slogan ou frases de efeito; presença ou não de informações e/ou orientações sobre cuidados para prevenção das arboviroses e promoção da saúde, observando se as peças tinham intencionalidade educativa. Ressalta-se que a pesquisa se desenvolveu com base de dados secundários, portanto, houve dispensa do Comitê de Ética em Pesquisa.

Além dos dados textuais contidos nos cartazes, foram considerados os achados encontrados a partir da descrição das peças.
Após a observação do material, emergiram as seguintes categorias temáticas: mobilização; orientação; e informação. Categorias essas que foram identificadas, a priori, com base na literatura prévia ${ }^{9}$ e validadas conforme os conteúdos encontrados nas campanhas. A primeira é compreendida como uma convocação de vontades para atuar em busca de um propósito comum ${ }^{17}$, no caso, a prevenção das arboviroses e a promoção da saúde. Dessa forma, além de trechos iluminados com o referido conceito, nela, foram considerados os slogans contidos nos cartazes, os quais são definidos como frase-tema de uma campanha que procura resumir e/ou definir seu posicionamento ${ }^{3}$. A categoria 'orientações' incluiu frases no modo imperativo e instruções sobre como organizar ou executar ações, em especial, para evitar criadouros do mosquito. No que se refere à 'informação', considerou-se o conceito apontado na introdução, ou seja, conteúdos ou conhecimentos que orientam a tomada de decisão e que têm a intenção de notificar ou compartilhar algo.

\section{Resultado e discussão}

Foram analisadas 17 peças das campanhas promovidas pelo MS no período de 2013 a 2017. Destacam-se as campanhas nacionais e o formato de cartaz, disponíveis no site institucional da pasta ministerial. Observou-se que, após o surgimento da chikungunya e da zika em 2014 e 2015, respectivamente, a instituição quase quadruplicou a média da produção anual das referidas peças. Em 2013, havia apenas um cartaz. No ano seguinte, o número de cartazes sextuplicou; em 2015, ficou em 3, passando para 4 em 2016 e 3 em 2017, saindo de 1 para 3,6 cartazes por ano conforme gráfico 1 . 
Gráfico 1. Quantidade de campanhas produzidas pelo Ministério da Saúde sobre as arboviroses (dengue, zika e chikungunya) de 2013 a 2017

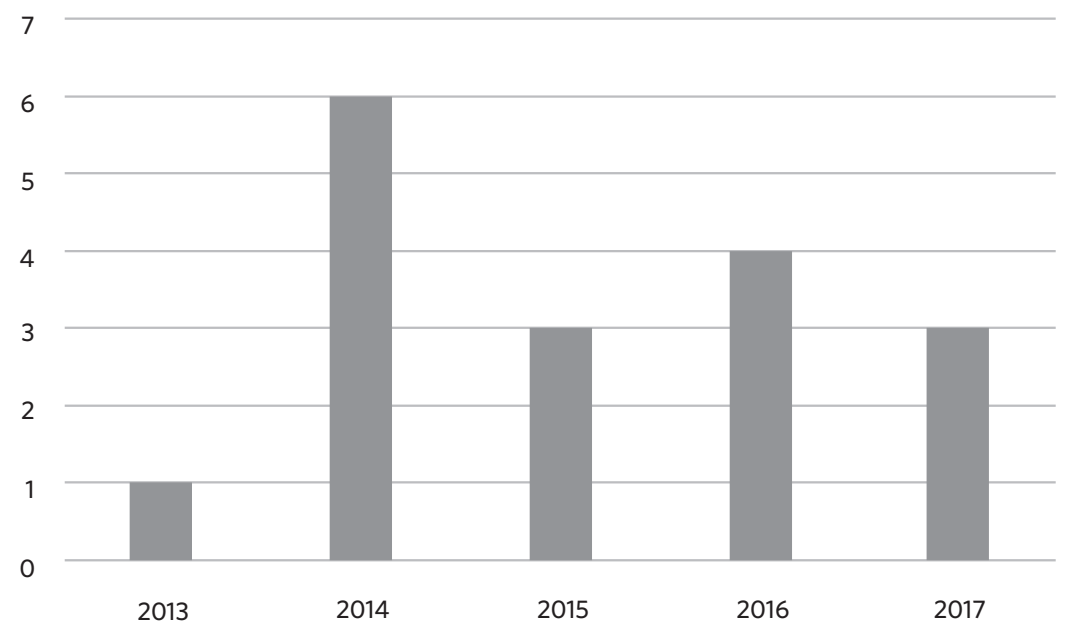

Fonte: Elaboração própria.

Brito $^{3}$ define cartaz como qualquer mensagem publicitária gráfica impressa em papel ou outro material. Destaca-se que seu tamanho, forma, arte, cores, disposição das informações e todas as outras características são personalizáveis conforme a intencionalidade e a mensagem que se deseja transmitir. Em geral, esses materiais gráficos são fixados em locais públicos onde há grande circulação de pessoas que se deseja alcançar. Configura-se um dos produtos mais comuns da publicidade e da propaganda, usado histórica e tradicionalmente em campanhas de saúde 2 . Essa adoção justifica-se, supostamente, por tratar-se de material gráfico-visual que pode ser visto e assimilado em poucos segundos, sem a necessidade de muitos esforços por parte do público a quem se destina.

Da observação dos cartazes analisados, percebe-se que as principais cores adotadas foram vermelho, amarelo, preto e branco, sendo que esta última é usada especialmente nos textos. No que se refere aos personagens e imagens observados nas peças, o gênero feminino é o mais evidente, aparecendo em sete delas, enquanto as figuras masculinas aparecem em apenas três. No tocante à raça e à cor, pessoas negras e pardas foram a maioria nas peças. Quanto à idade dos personagens, apenas dois cartazes continham pessoas de meia idade, e as duas eram mulheres. Apesar dos esforços explícitos de representar a maioria da população brasileira, mulheres e pessoas negras, ainda há ausência de pessoas com faixa etária a partir de 50 anos de idade.

Esses achados têm relação direta com a primeira categoria observada, a mobilização. As cores são fortes, os personagens são jovens, e todos os trechos de mobilização têm apelo a uma linguagem bélica que pede para combater, lutar, atacar e eliminar o vetor ou a doença. Constata-se uma responsabilização da população em trechos como: 'Um mosquito pode prejudicar uma vida. E o combate começa por você'; 'O perigo aumentou. E a responsabilidade de todos também’; e 'Sábado da faxina. Não dê folga para o mosquito da dengue'. No entanto, deveria ocorrer um trabalho integrado, em que todos se sentissem corresponsáveis, com a compreensão de que 
preocupações além da eliminação do vetor são necessárias, sobretudo quanto à relação das pessoas com o ambiente e o entendimento delas enquanto cidadãs ${ }^{\mathbf{1 3}, \mathbf{1 8}}$.

A presença das frases 'Melhorar sua vida, nosso compromisso' e 'É o Brasil cuidando da sua gente', em 2013 e 2015, respectivamente, até sugeriria tal compreensão, todavia, trata-se apenas de uma estratégia de comunicação institucional criticada por Bucci ${ }^{19}$, que a entende como uso indevido dos recursos públicos e do princípio da publicidade para promoção de interesses governamentais e partidários. Nesse sentido, a lógica transmissiva e campanhista mais uma vez se mostra insuficiente para a mobilização ${ }^{\mathbf{2 0}}$, em especial, em uma peça impressa, com pouca acessibilidade que, em geral, se perde em meio a outras do mesmo suporte em murais de unidades de saúde, isso quando chegam lá.

Essa discussão vai ao encontro do que se observou quanto à presença dos nomes das secretarias estaduais e municipais na faixa em que ficam as logomarcas das instituições envolvidas na campanha. Estas só aparecem nas campanhas de 2015, quando o MS declarou situação de Emergência em Saúde Pública de Importância Nacional (Espin) devido ao elevado número de casos das arboviroses e à suspeita da relação do zika com a microcefalia $^{21}$. Nesta época, houve um trabalho articulado entre diversas esferas governamentais e setores públicos, com diferentes estratégias. Não obstante, este cessou após o fim da crise. O momento serviu para deixar claro que não só é possível realizar um trabalho articulado, como a efetividade é muito maior, uma vez que houve a redução dos casos de microcefalia?.

No que se refere à categoria 'informação', observou-se que foram os conteúdos mais frequentes nos cartazes. No tocante à disponibilização do conteúdo, os destaques foram colocados, em geral, no centro ou canto superior esquerdo das peças, especialmente os slogans. Diversos trabalhos apontam que, nesse tipo de material, o título recebe maior atenção visual que o corpo do texto, apresentado em tamanho menor, como nas peças analisadas, embora contenham mais informações. Além disso, esses estudos também destacam que as pessoas tendem a, rapidamente, direcionar o olhar para o canto superior esquerdo do anúncio ${ }^{22}$.

Ao se considerar a perspectiva de técnicas de comunicação comercial, pode-se afirmar que o layout utilizado pelo MS na produção dos cartazes analisados está adequado, contudo, se considerarmos o objetivo das peças - prevenção das arboviroses e promoção da saúde da população -, e não a venda de um produto ou serviço, afinal compreende-se o conceito ampliado da saúde, pode-se também, ao menos, ficar na dúvida. Trata-se de comunicação pública com uma função complexa; e esperar que a lógica comercial sirva para isso é, no mínimo, incoerente com o objetivo que se almeja ao veiculá-la' ${ }^{19}$.

O Disque Saúde apareceu em 16 das 17 peças, entretanto, praticamente sem destaque ou orientações sobre a forma que tal ferramenta pode ser utilizada em relação ao tema das arboviroses. $\mathrm{O}$ endereço do site - saude. gov.br -, que desponta logo abaixo do Disque Saúde, tem menos visibilidade ainda. Como dado central e recomendação para acesso a outras informações da campanha, o endereço do site, não o geral desta vez, mas do combate ao vetor das doenças - saude.gov.br/combateaedes -, só consta nas peças veiculadas em 2017. Também sobre interatividade e articulação a outras mídias de comunicação, observou-se a ausência das mídias sociais digitais nos cartazes produzidos em 2014, 2015 e na campanha 'Zika Zero' de 2016.

Outro detalhe interessante suscitado da análise dos cartazes é que o 'mosquito' foi mencionado em 16 das 17 peças, e a imagem do vetor aparece em todas elas. Em 2014, as peças trazem uma nuvem dos insetos. No ano seguinte, ele é um detalhe acima das palavras 'dengue e chikungunya'. Em 2016, na campanha 'Zika Zero', ele surge estilizado como um vilão de desenho animado, com olhos esbugalhados, cuja aparência não é fiel à do inseto. No mesmo ano, fora as campanhas do 'Zika Zero' e em 
2017, o Aedes aparece em negativo, ou seja, uma silhueta com o sinal de proibido em cima.

As informações mais frequentes nas peças foram afirmações sobre o mosquito ser o transmissor das doenças e quanto à novidade da situação: 'O mosquito da dengue agora também transmite a chikungunya'; 'O mosquito da dengue pode matar e pode causar microcefalia em bebês'. A dengue é a doença mais citada, duas vezes mais que a zika ou a chikungunya. Os sintomas estão em apenas dois cartazes, todavia, consequências ou sequelas advindas dos agravos começaram a ser a principal mensagem dos cartazes a partir de 2016, em geral sobre a morte: 'A dengue mata'; e sobre a microcefalia: 'O mosquito da dengue pode matar e pode causar microcefalia em bebês'. Não se observou o cuidado em tranquilizar as pessoas após essas afirmações ${ }^{23}$.

Na peça publicada em 2016, não foram identificadas informações acerca do período de latência entre os ovos para o nascimento de novos vetores e afirmações, mas a informação de que o vírus Zika pode ser transmitido por relação sexual sem proteção e que mesmo grávidas as mulheres deveriam usá-la chamou bastante atenção. Esses achados vão ao encontro das discussões acerca da confirmação ou não da relação do vírus com a microcefalia. Atendendo às diretrizes da comunicação de risco, o MS transmitiu informações relevantes no contexto de crise, mesmo diante do cenário de incerteza, pois era necessário prevenir a infecção dos bebês cujas mães estavam gestantes no período ${ }^{24,25}$.

A categoria 'orientações' está toda escrita de forma impositiva e focada na prevenção: 'Mantenha a lixeira fechada', 'Elimine os criadouros' e 'Tampe os toneis e caixas d'água'. Estas remetem o usuário aos cuidados que devem ser tomados, no entanto, desvinculadas do universo significativo do indivíduo e sem explicar os porquês das ações, as implicações práticas dos cuidados orientados. Os possíveis criadouros do vetor das arboviroses - utensílios como tonéis, pneus, garrafas PET, entre outras - ilustraram 10 das 18 campanhas, sendo que a campanha de 2014 era o centro das atenções com imagens de caixa d'água destampada, garrafa PET, saco de lixo aberto, tonel e vasinho de planta transformando-se em nuvem de mosquitos da dengue.

As grávidas tiveram atenção especial da comunicação analisada ao serem orientadas sobre o uso de repelente, preservativos e à realização do pré-natal em campanha de prevenção às arboviroses. Quanto à orientação de procurar serviços de saúde, esta foi quase inexistente nos cartazes. A orientação de buscar outras informações sobre a doença no site do MS apareceu nos últimos produtos analisados, ao mesmo tempo que as fake news foram um grande problema no momento da crise ${ }^{\mathbf{2 4}}$. Constatou-se que uma peça com orientações distribuída em 2016 foi reaproveitada na campanha de 2017; e a frase 'Conheça histórias de vida devastadas por essas doenças', nas produções de 2017, é, no mínimo, curiosa, pois nesse ano, a campanha ignorou os cuidados e passou a trabalhar com histórias de personagens reais que tiveram perdas e sequelas relacionadas com as arboviroses em questão.

Nota-se que a comunicação realizada pelo MS ainda se preocupa somente com a prevenção das doenças e segue o padrão campanhista de 1920 para executar suas ações. As estratégias tradicionais de transmissão de informações verticalizadas e de orientações responsabilizadoras ignoram as diretrizes de uma comunicação educativa e promotora de saúde, o que, segundo Paulo Freire, não produz significações e transformações na vida dos indivíduos ${ }^{13}$. Na ótica da comunicação educativa, essas significações são imprescindíveis para que haja transformações significativas para superação dos agravos em saúde. A forma padronizada de realizar a comunicação ainda é o modelo tradicional, e não o baseado em uma educação emancipatória contando com um sujeito protagonista do seu saber.

Destaca-se que as ações não podem ser meramente preventivas, mas capazes de promover a saúde dos indivíduos, entendendo-se por promoção a capacitação da comunidade 
para atuar na melhoria da qualidade de vida e saúde do próprio indivíduo e comunidade. Assim, a promoção da saúde deixa de ser uma responsabilidade só dos profissionais da saúde e passa a ser uma responsabilidade de todos, além de direcionar que o indivíduo busque uma vida saudável e o bem-estar individual e coletivo ${ }^{7}$.

\section{Considerações finais}

Não se percebeu uma comunicação educativa ou promotora de saúde nas campanhas analisadas. Mais uma vez, constataram-se a transmissão de informações e a imposição de orientações, distante daquilo proposto pela comunicação educativa, que pressupõe ações pensadas conforme as necessidades dos usuários. Estas sequer foram observadas nos cartazes no período analisado.

Ressalta-se que pensar ações de controle e combate a esses vetores, bem como de prevenção das arboviroses, perpassa, impreterivelmente, ações de informação e comunicação em saúde; e que estas sejam, ao mesmo tempo, educativas. Isso exige aos gestores e profissionais de saúde a elaboração de estratégias dialógicas que fomentem o agir comunicativo e a transformação das práticas cotidianas, além de uma visão holística do problema em questão, afinal de contas, a prevenção e o controle das arboviroses não dependem somente da eliminação dos criadouros do Aedes.

A concepção de campanhas com peças isoladas ou práticas comunicacionais centradas nos indivíduos e na realidade em que estes estão inseridos, bem como na efetiva transformação dessa realidade, não podem ser vistas como práticas educativas. Ademais, as campanhas produzidas pelo MS e aqui analisadas são apenas informativas.
A crítica ao fato de se tratar de uma peça com pouco espaço para o diálogo - afinal, trata-se de um material gráfico impresso não impede que a linguagem, as imagens e as possibilidades de interação a partir do suporte sejam infinitas. Para isso, é preciso compreender que o público a quem se destina é composto por pessoas dotadas de direito e que podem e devem ser tratadas para além de uma recepção passiva de conteúdo.

\section{Colaboradoras}

Andrade NF (0000-0002-6137-4335)* elaborou o primeiro manuscrito do artigo, a partir de suas pesquisas durante a realização do mestrado profissional em Saúde Coletiva pelo Programa de Pós-Graduação em Saúde Coletiva da Universidade de Brasília. Prado EAJ (0000-0002-2731-5155)* contribuiu para as análises dos resultados brutos de campo, a partir da participação no grupo de estudos vinculado à pesquisa de origem ao projeto de mestrado. Albarado AJ (0000-00032519-7690)* contribuiu para os resultados e discussões do artigo e para a revisão final, a partir da participação no grupo de estudos vinculado à pesquisa de origem do projeto de mestrado. Sousa MF (0000-0001-69499194)* coordenadora geral do projeto de pesquisa que ancora o estudo, participou da revisão final do manuscrito e da formatação do referencial em Vancouver. Mendonça AVM (0000-0002-1879-5433)* contribuiu para a revisão final do manuscrito, apontamentos sobre os estudos referentes ao Laboratório de Educação, Informação e Comunicação em Saúde da Universidade de Brasília (do qual é coordenadora), e ainda colaborou para as análises fruto do estudo de mestrado, do qual foi orientadora principal. 


\section{Referências}

1. Duarte J, Veras L. Glossário de comunicação pública. Brasília, DF: Casa das Musas; 2006.

2. Pessoni A. História da interface comunicação e saúde. In: Paulino FO, organizador. Comunicação e Saúde. Brasília, DF: Casa das Musas; 2009. p. 31-42.

3. Brito BP. Dicionário de Propaganda [internet] 2007. [acesso em 2018 julho 8]. Disponível em: http://www. brenobrito.com/files/Dicionario_da_Propaganda.pdf.

4. Organização Pan-Americana da Saúde. Organização Mundial da Saúde. Boletim semanal \#10-Resposta da representação da OPAS/MS no Brasil para a epidemia do vírus da Zika e suas consequências [internet]. 2016. [acesso em 2017 ago 29]. Disponível em: paho. org/bra/images/stories/SalaZika/boletim\%20quinzenal\%2010\%20zika.pdf?ua=1.

5. Brasil. Ministério da Saúde. Monitoramento dos casos de dengue, febre de chikungunya e febre pelo vírus Zika até a Semana Epidemiológica. Boletim epidem. [internet]. 2016 [acesso em 2017 set 3]; 47(27):1-10. Disponível em: http://portalsaude.saude.gov.br/images/pdf/2016/junho/30/2016-021.pdf.

6. Czeresnia D. Conceito de saúde e a diferença entre prevenção e promoção. In: Czeresnia D, Freitas CM, organizadores. Promoção da saúde: conceitos, reflexões, tendências. 2. ed. Rio de Janeiro: Fiocruz; 2012. p. 43-57.

7. Brasil. Ministério da Saúde. As Cartas da Promoção da Saúde [internet]. Brasília, DF: MS; 2002. (Série B. Textos Básicos em Saúde). [acesso em 10 jul 2015]. Disponível em http://bvsms.saude.gov.br/bvs/publicacoes/cartas_promocao.pdf.

8. Salazar L. Evaluación de efectividad en promoción de la salud: guia de evaluación rápida. Bogotá, DF: Centro para el Desarrollo y Evaluación de Políticas y Tecnología en Salud Pública; Universidad del Valle; Organización Panamericana de la Salud, 2004.

9. Albarado AJ, Prado EJ, Mendonça AVM. Um, dois, três - gravando: as campanhas audiovisuais do Ministério da Saúde sobre dengue, chikungunya e Zika de 2014 a 2017. Reciis - Rev Eletron Comun Inf Inov Saúde [internet]. 2019 [acesso em 2019 set 7]; 13(1):19816278. Disponível em: https://www.reciis.icict.fiocruz. br/index.php/reciis/article/view/1596.

10. Organización Panamericana de la Salud. Educación para la salud: un enfoque integral. Washington, DF: OPS; 1995. (Série HSS/SILOS, n. 37).

11. Wolton D. Dominique. Informar não é comunicar. Porto Alegre: Sulina; 2010.

12. Soares IO. Educomunicação: um campo de mediações. Comum. Edu. 2000; (19):12-24.

13. Freire P. Pedagogia da autonomia: saberes necessários à prática docente. São Paulo: Paz e Terra; 1996.

14. Miranda A, Simeão E. A conceituação de massa documental e o ciclo de interação entre tecnologia e o registro do conhecimento. In: Nakayama $\mathrm{H}$, organizador. Análise da informação. Brasília, DF: UnB; 2002.

15. Ministério da Saúde. Campanhas [internet]. [acesso em 2017 ago 9]. Disponível em: portalms.saude.gov. br/campanhas.

16. Vasconcelos WRM, Oliveira-Costa MS, Mendonça AVM. Promoção ou prevenção? Análise das estratégias de comunicação do Ministério da Saúde no Brasil de 2006 a 2013. Reciis - Rev Eletron Comun Inf Inov Saúde. 2016; 10(2):1-11.

17. Mosquera Vásquez M. Comunicación en salud: conceptos, teorías y experiencias. Comminit, La iniciativa de la comunicación [internet]. 2003 [acesso em 2017 ago 9]. Disponível em: http://www.comminit. com/en/node/150400.

18. Buss PM. Uma introdução ao conceito de promoção da saúde. In: Czeresnia D, Freitas CM, organizadores. Promoção da saúde: conceitos, reflexões, tendências. 2. ed. Rio de Janeiro: Fiocruz; 2009. p. 19-42. 
19. Bucci E. O Estado de Narciso: a comunicação pública a serviço da vaidade particular. São Paulo: Companhia das Letras; 2015.

20. Tóth M, Laro R. O potencial limitado das campanhas massivas de comunicação para a transformação de comportamentos sociais. In: Paulino FO, organizador. Comunicação e Saúde. Brasília, DF: Casa das Musas; 2009. p. 45-53.

21. Aguiar R, Araújo IS. A mídia em meio às 'emergências' do vírus Zika: questões para o campo da comunicação e saúde. Reciis - Rev Eletron Comun Inf Inov Saúde [internet]. 2016 [acesso em 2018 jan 9]; 10(1):115. Disponível em: https://www.reciis.icict.fiocruz. br/index.php/reciis/article/view/1088.

22. Kawano DR, Jardim ACA, Shimabukuron M, et al. Campanhas de combate ao Aedes aegypti na região amazônica: uma análise de atenção visual com o uso do eye tracker. Sig. Consumo. 2017; 9(2):106-120.
23. Backer TE, Rogers EM, Sopory P. Designing health communication campaigns: What works? Thousand Oaks: Sage Publications; 1992.

24. Henriques CM. A Surpresa e o Grito. In: Brasil. Ministério da Saúde. Vírus Zika no Brasil: a resposta do SUS. Brasília, DF: Ministério da Saúde; 2017. p. 15-25.

25. Turcato MA. Comunicação como Estratégia. In: Brasil. Ministério da Saúde. Vírus Zika no Brasil: a resposta do SUS. Brasília, DF: Ministério da Saúde; 2017. p. 47-49.

Recebido em 29/09/2019

Aprovado em 10/06/2020

Conflito de interesses: inexistente

Suporte financeiro: não houve 